\title{
ENRAIZAMENTO E ACLIMATIZAÇÃo DE PLANTAS MiCROPROPAGADAS DE AMOREIRA-PRETA CV. BRAZOS ${ }^{1}$
}

\author{
CAROLINA SMANHOTTO SCHUCHOVSKI AUGUSTO ${ }^{2}$, LUIZ ANTONIO BIASI ${ }^{3}$, CHARLES ALLAN TELLES $^{4}$
}

RESUMO - O presente trabalho estudou as fases finais do processo de micropropagação, incluindo o enraizamento e a posterior aclimatização da amoreira-preta cv. Brazos. Os experimentos foram realizados no Laboratório de Micropropagação de Plantas da UFPR, Curitiba-PR, no período de março de 2000 a julho de 2001. No enraizamento in vitro com ou sem imersão em AIB, obteve-se mais de $95 \%$ de enraizamento nos dois tratamentos. No experimento de enraizamento ex vitro, com microestacas provenientes da multiplicação com diferentes citocininas, as taxas de enraizamento e sobrevivência foram de $100 \%$. Na fase final, testou-se a influência da sacarose do meio de cultura de enraizamento in vitro na posterior aclimatização. Em todos os tratamentos, houve $100 \%$ de sobrevivência. Conclui-se que pode ser realizado um eficiente enraizamento in vitro sem AIB e sem a adição de sacarose ao meio de cultura, com posterior aclimatização em túnel plástico ou, ainda, realizar o enraizamento ex vitro e aclimatização em casa de vegetação com nebulização intermitente.

Termos para indexação: amora-preta, Rubus sp., micropropagação.

\section{ROOTING AND ACCLIMATIZATION OF MICROPROPAGATED PLANTS OF BLACKBERRY CV. BRAZOS}

ABSTRACT - The present work studied the final stages of blackberry cv. Brazos micropropagation, including rooting and acclimatization. The experiments were carried out in the Plant Micropropagation Laboratory at UFPR, Curitiba-PR, during March 2000 until July 2001 . In the in vitro rooting with or without immersion in IBA, the percentage of rooting was higher than $95 \%$ in both treatments. In the experiment of ex vitro rooting, with micro-shoots proceeding from the multiplication with different cytokinins, the rooting and survival rates were of $100 \%$. In the final stage it was tested the influence of sucrose of the in vitro rooting media on the acclimatization. All the treatments showed $100 \%$ of survival. It can be concluded that an efficient in vitro rooting can be realized without both IBA and sucrose in the culture media with acclimatization under plastic tunnel or ex vitro rooting and acclimatization under intermittent mist in a greenhouse.

Index Terms: blackberry, Rubus sp., micropropagation.

\section{INTRODUÇÃO}

A amoreira-preta é uma espécie cutivada nas regiões Sul e Sudeste do Brasil. O processo de micropropagação apresenta diversas vantagens em relação aos métodos tradicionalmente utilizados na propagação de amoreira-preta, especialmente quanto à maior sanidade das mudas. Uma importante etapa da micropropagação refere-se ao enraizamento das microestacas obtidas e posterior aclimatização das plantas enraizadas.

O processo de enraizamento de microestacas é influenciado por diversos fatores, entre os quais os reguladores de crescimento (Assis \& Teixeira, 1998). Dentre os promotores de enraizamento, encontra-se o AIB (ácido indolbutírico), que tem sido bastante usado por não causar fitotoxicidade aos explantes em concentrações relativamente altas e por ser eficiente em uma grande variedade de espécies. Além do método de enraizamento in vitro de microbrotos, testado por diversos autores (Borgman \& Mudge, 1986; Deng \& Donnelly, 1993a; Deng \& Donnelly, 1993b; Karakullukçu et al., 1993), tem sido testado o enraizamento ex vitro diretamente em substrato (Jin et al., 1992; Avitia García \& Castillo González, 1992). Este último apresenta como vantagens a diminuição das dificuldades associadas à sobrevivência e ao desenvolvimento das plantas cultivadas in vitro (Avitia García \& Castillo González, 1992; Sobczykiewicz, 1992) e a redução dos custos de produção da micropropagação (Hoepfner \& Nestby, 1991).

Na fase de aclimatização, Deng \& Donnelly (1993b) destacam que este processo ex vitro tem altos custos e demanda longo tempo para a obtenção das mudas. Portanto, sugerem mudanças no ambiente da cultura, entre os quais, a redução da concentração de sacarose nos estádios finais de micropropagação, para promover o endurecimento in vitro, buscando aumentar a capacidade fotossintética das plantas.
O presente trabalho teve como objetivos definir a necessidade ou não da aplicação de AIB nas microestacas para o enraizamento in vitro; verificar se o enraizamento ex vitro e se a aclimatização são influenciados pelas diferentes citocininas da fase de multiplicação e determinar se a sacarose no meio de cultura na etapa de enraizamento in vitro interfere na aclimatização em casa de vegetação com nebulização e em túnel plástico.

\section{MATERIAL E MÉTODOS}

Os estudos foram realizados no Laboratório de Micropropagação de Plantas e na casa de vegetação do Departamento de Fitotecnia e Fitossanitarismo do Setor de Ciências Agrárias da Universidade Federal do Paraná, em Curitiba-PR, tendo início em março de 2000 e término em julho de 2001. Para os três experimentos, utilizaram-se as brotações individualizadas (microestacas), provenientes da formação do tipo 'tufos' do $4^{\circ}$ subcultivo da multiplicação in vitro. Para iniciar o cultivo in vitro foram utilizados segmentos nodais retirados das brotações novas de plantas matrizes mantidas em casa de vegetação.

No enraizamento in vitro, testaram-se microestacas imersas ou não em solução $1 \mathrm{mM}$ de AIB (Sigma®), por 2 segundos. O meio de cultura utilizado foi o MS/2 (Murashige \& Skoog, 1962) com a concentração de macro e micronutrientes reduzida à metade, acrescido de 100 mg.L L $^{-1}$ de mio-inositol, 30 g.L L $^{-1}$ de sacarose e 6 g.L ${ }^{1}$ de ágar $\left(\right.$ Micromed $\left.{ }^{\circledR}\right)$, sem reguladores de crescimento e pH 5,8, esterilizado em autoclave por 20 minutos a $120^{\circ} \mathrm{C}$ e $1,5 \mathrm{~atm}$. Após a repicagem em câmara de fluxo laminar, os frascos com capacidade de $250 \mathrm{~mL}$ e fechados com papel alumínio, foram colocados em sala de cultivo com temperatura de $25 \pm 2^{\circ} \mathrm{C}$, umidade relativa do ar de $65 \%$ e fotoperíodo de 16 horas, com iluminação por lâmpadas fluorescentes do tipo luz do dia e irradiância de $40 \mu \mathrm{mol} \cdot \mathrm{m}^{-2} \cdot \mathrm{s}^{-1}$.

\footnotetext{
${ }_{1}^{1}$ (Trabalho 59-2006). Recebido: 08-05-2006. Aceito para publicação: 04-09-2006.

${ }^{2}$ Eng. Agr., M.Sc., Programa de Pós-Graduação em Agronomia - Produção Vegetal. UFPR. Curitiba-PR. E-mail: carolina@ proconsult.com.br.

${ }^{3}$ Eng. Agr, Dr., Professor Adjunto. Departamento de Fitotecnia e Fitossanitarismo. Setor de Ciências Agrárias. UFPR. Caixa Postal 19.061. CEP 81531-990.

Curitiba-PR. Fone: (41) 3350-5682. E-mail: biasi@ufpr.br. Bolsista de Produtividade em Pesquisa do CNPq

${ }^{4}$ Eng. Agr., M.Sc., Programa de Pós-Graduação em Agronomia - Produção Vegetal. UFPR. Curitiba-PR. E-mail: chalés.allan@bol.com.br.
} 
Foram utilizadas 12 microestacas por parcela, com 4 repetições. A avaliação foi realizada após 41 dias.

Numa segunda etapa, testou-se o enraizamento ex vitro das microestacas provenientes da multiplicação com diferentes citocininas, BAP (6-benzilaminopurina), CIN (cinetina), ZEA (zeatina) e 2iP (2-isopenteniladenina) nas concentrações de 5 e $10 \mu \mathrm{M}$ ), além da testemunha. As microestacas foram colocadas em bandejas de isopor contendo substrato Plantmax ${ }^{\circledR}$ para enraizamento e aclimatização, em câmara de nebulização intermitente, com rega automática de 15 segundos a cada 30 minutos. Foram utilizadas 7 a 12 microestacas por parcela, com 4 repetições. A primeira avaliação foi realizada após 36 dias, e a segunda avaliação, 57 dias após o início do experimento.

No estudo de aclimatização das mudas após o enraizamento in vitro testaram-se dois fatores: a presença ou ausência de sacarose na etapa de enraizamento e o local de aclimatização (em câmara de nebulização ou em túnel plástico sem nebulização). Utilizou-se o meio de cultura MS/2 conforme acima descrito no primeiro experimento, sem regulador de crescimento. Os tratamentos resultaram da combinação do enraizamento em meio de cultura sem e com 30 g.L. L $^{-1}$ de sacarose e da aclimatização em túnel plástico sem nebulização ou em câmara de nebulização. Os explantes enraizados foram colocados em bandejas de isopor contendo substrato Plantmax ${ }^{\circledR}$. A câmara de nebulização intermitente possuía rega automática de 15 segundos a cada 30 minutos e no túnel plástico a irrigação foi realizada por aspersão a cada dois dias. O esquema experimental foi um fatorial $(2 \mathrm{x} 2)$, com 4 tratamentos, 4 repetições e 12 microestacas por parcela.

Todos os experimentos tiveram o delineamento inteiramente ao acaso, e os dados obtidos foram analisados pelo teste de Bartlett, a análise de variância e o teste de comparação de médias pelo de
Tukey, a 5\%, no programa de computador MSTAT.

\section{RESULTADOS E DISCUSSÃO}

Na Tabela 1, observam-se os resultados do experimento de enraizamento in vitro com ou sem AIB. Obtiveram-se taxas de enraizamento de $95 \%$ e de $100 \%$, respectivamente, que não foram estatisticamente diferentes entre si. Com relação ao comprimento de raízes, número de folhas por planta e altura das plantas, também não se constatou diferença entre os tratamentos. Houve apenas diferença com relação ao número de raízes por explante. $\mathrm{O}$ tratamento com imersão em AIB apresentou 4,5 raízes, contra 3,1 raízes do tratamento sem imersão em AIB. Avitia García \& Castillo González (1992), no entanto, não encontraram diferenças entre os tratamentos com AIB e a testemunha, no número de raízes nas cultivares testadas de amoreira.

Vários autores descrevem a importância da utilização de auxinas no enraizamento de espécies in vitro. $\mathrm{O}$ que se pode constatar é que não houve necessidade de imersão em AIB para o enraizamento da cultivar Brazos. Essa ocorrência provavelmente, se deve à facilidade de enraizamento da espécie e, particularmente, da cultivar testada. Segundo Assis \& Teixeira (1998), há várias evidências de que a formação de raízes é geneticamente controlada, pois há bastante variação entre espécies e mesmo entre clones.

Com resultados semelhantes ao encontrado no presente trabalho, Avitia García \& Castillo González (1992) alcançaram 77 a $100 \%$ de sucesso no enraizamento ex vitro, sem a utilização de reguladores de crescimento para o enraizamento de amoreira. Da mesma maneira, Radmann et al. (2003) não observaram diferença no enraizamento de amoreira-preta cv. Ébano com diferentes concentrações de AIB, variando entre 0 a $1 \mu \mathrm{M}$. Ramirez del Castillo

TABELA 1 - Efeito da imersão ou não de microestacas em solução de AIB por 2 segundos no enraizamento, número de raízes, comprimento das raízes, altura das plantas e número de folhas por planta de amoreira-preta (Rubus sp.) cv. Brazos. Curitiba - PR. 2001.

\begin{tabular}{lccccc}
\hline Tratamento & $\begin{array}{c}\text { Observações } \\
\left(\mathrm{n}^{\circ}\right)\end{array}$ & $\begin{array}{c}\text { Plantas enraizadas } \\
(\%)\end{array}$ & $\begin{array}{c}\text { Raízes por planta } \\
\left(\mathrm{n}^{\circ}\right)\end{array}$ & $\begin{array}{c}\text { Comprimento das } \\
\text { raízes } \\
(\mathrm{cm})\end{array}$ & $\begin{array}{c}\text { Altura das plantas } \\
(\mathrm{cm})\end{array}$ \\
\hline Sem AIB & 48 & $100,0^{2}$ & $3,1 \mathrm{~b}^{1}$ & $1,78^{2}$ & $\begin{array}{c}\text { Folhas por planta } \\
\left(\mathrm{n}^{\circ}\right)\end{array}$ \\
Com AIB & 48 & 95,8 & $4,5 \mathrm{a}$ & 1,53 & $2,25^{2}$ \\
\hline C.V. $(\%)$ & - & 4,56 & 11,19 & 15,82 & 9,49 \\
\hline
\end{tabular}

${ }^{1}$ Médias seguidas por letras distintas na coluna diferem estatisticamente entre si, pelo teste de Tukey, a $5 \%$ de probabilidade.

${ }^{2}$ Médias na coluna não diferem significativamente pelo teste $\mathrm{F}$, a $5 \%$ de probabilidade, realizado na análise de variância.

TABELA 2 - Efeito das citocininas da fase de multiplicação, BAP (6-benzilaminopurina), CIN (cinetina), ZEA (zeatina) e 2iP (2-isopenteniladenina) na primeira avaliação $\left(1^{\mathrm{a}}=36\right.$ dias $)$ e segunda avaliação $\left(2^{\mathrm{a}}=57\right.$ dias $)$ para o enraizamento, sobrevivência, altura e número de folhas por planta da amoreira-preta (Rubus sp.) cv. Brazos. Curitiba - PR. 2001.

\begin{tabular}{|c|c|c|c|c|c|c|c|c|}
\hline \multirow[t]{2}{*}{ Tratamento } & \multirow[t]{2}{*}{$\begin{array}{l}\text { Observações } \\
\qquad\left(n^{\circ}\right)\end{array}$} & \multirow{2}{*}{$\begin{array}{l}\text { Plantas enraizadas } \\
(\%)\end{array}$} & \multicolumn{2}{|c|}{$\begin{array}{c}\text { Sobrevivência das plantas } \\
(\%)\end{array}$} & \multicolumn{2}{|c|}{$\begin{array}{l}\text { Altura das plantas } \\
\qquad(\mathrm{cm})\end{array}$} & \multicolumn{2}{|c|}{ Folhas por planta $\left(\mathrm{n}^{\circ}\right)$} \\
\hline & & & $1^{\mathrm{a}}$ & $2^{\mathrm{a}}$ & $1^{\mathrm{a}}$ & $2^{\mathrm{a}}$ & $1^{\mathrm{a}}$ & $2^{\mathrm{a}}$ \\
\hline Testemunha & 31 & 100 & 100 & 100 & $5,88 \mathrm{abc}^{1}$ & $28,83^{1}$ & $11,5 \mathrm{ab}^{1}$ & $40,4^{1}$ \\
\hline $5 \mu \mathrm{M}$ de BAP & 48 & 100 & 100 & 100 & $5,80 \mathrm{abc}$ & 34,20 & $10,3 \mathrm{ab}$ & 40,4 \\
\hline $10 \mu \mathrm{M}$ de BAP & 48 & 100 & 100 & 100 & $4,16 c$ & 27,95 & $8,9 b$ & 36,0 \\
\hline $5 \mu \mathrm{M}$ de $\mathrm{CIN}$ & 35 & 100 & 100 & 100 & $5,18 \mathrm{bc}$ & 27,13 & $9,8 \mathrm{~b}$ & 35,1 \\
\hline $10 \mu \mathrm{M}$ de CIN & 48 & 100 & 100 & 100 & $5,20 \mathrm{bc}$ & 38,17 & $9,0 \mathrm{~b}$ & 38,7 \\
\hline $5 \mu \mathrm{M}$ de $\mathrm{ZEA}$ & 48 & 100 & 100 & 100 & $7,22 \mathrm{a}$ & 34,03 & $14,3 \mathrm{a}$ & 40,4 \\
\hline $10 \mu \mathrm{M}$ de $\mathrm{ZEA}$ & 36 & 100 & 100 & 100 & $6,10 \mathrm{ab}$ & 34,85 & $12,2 \mathrm{ab}$ & 41,7 \\
\hline $5 \mu \mathrm{M}$ de $2 \mathrm{iP}$ & 31 & 100 & 100 & 100 & $5,52 \mathrm{abc}$ & 35,50 & $11,8 \mathrm{ab}$ & 39,4 \\
\hline $10 \mu \mathrm{M}$ de $2 \mathrm{iP}$ & 41 & 100 & 100 & 100 & $5,70 \mathrm{abc}$ & 33,20 & $10,4 \mathrm{ab}$ & 38,8 \\
\hline C.V. $(\%)$ & - & - & - & - & 12,92 & 31,20 & 16,68 & 12,13 \\
\hline
\end{tabular}

${ }^{1}$ Médias seguidas por letras distintas na coluna diferem estatisticamente entre si, pelo teste de Tukey, a 5\% de probabilidade. 
TABELA 3 - Efeito da sacarose do meio de cultura de enraizamento in vitro e do método de aclimatização na sobrevivência, altura e número de folhas por planta de amoreira-preta (Rubus sp.) cv. Brazos. Curitiba - PR. 2001.

\begin{tabular}{lccc}
\hline Meio de cultura & Sobrevivência das plantas (\%) & Altura das plantas $(\mathrm{cm})$ & Folhas por planta $\left(\mathrm{n}^{\circ}\right)$ \\
\hline Com sacarose & 100 & $2,91 \mathrm{a}^{1}$ & $9,3^{2}$ \\
Sem sacarose & 100 & $2,28 \mathrm{~b}$ & 9,1 \\
\hline Método de aclimatização & & & $9,7 \mathrm{a}^{1}$ \\
\hline Câmara de nebulização & 100 & $2,15 \mathrm{~b}^{1}$ & $8,7 \mathrm{~b}$ \\
Túnel plástico & 100 & $3,04 \mathrm{a}$ & 5,23 \\
\hline C.V. (\%) & - & 10,43 & \\
\hline
\end{tabular}

${ }^{1}$ Médias seguidas por letras distintas na coluna diferem estatisticamente entre si, pelo teste de Tukey, a 5\% de probabilidade.

${ }^{2}$ Médias na coluna não diferem significativamente pelo teste $\mathrm{F}$, a 5\% de probabilidade, realizado na análise de variância.

\& Angarita Zerda (1990) também observaram que a ausência de reguladores de crescimento ou a concentração muito baixa de auxinas é recomendada para induzir raízes em espécies de Rubus. Dantas et al. (2000) encontraram o melhor enraizamento da amoreira-preta cv. Caingangue no meio de cultura sem a auxina ANA (ácido naftalenoacético). Essas informações reforçam a facilidade de enraizamento da amoreira-preta, dispensando a utilização de auxinas.

No experimento de enraizamento ex vitro com microestacas provenientes da fase de multiplicação com diferentes citocininas, pode-se observar que não houve diferença de sobrevivência e enraizamento entre os diversos tratamentos, onde todos alcançaram taxas de $100 \%$ de enraizamento e sobrevivência (Tabela 2). Esse fato novamente comprova a facilidade de enraizamento da espécie. Mesmo as microestacas menores, provenientes dos tratamentos com BAP na fase de multiplicação, tiveram facilidade no enraizamento e aclimatização. Diferentemente do encontrado por Hoepfner et al. (1996), em que as microestacas derivadas do meio de cultura com BAP tiveram uma porcentagem maior de enraizamento do que as derivadas de meio de cultura com TDZ (thidiazuron). No presente trabalho, a única diferença ocorreu em relação ao número de folhas por planta e à altura das plantas, sendo que, em ambas as variáveis, os melhores tratamentos foram ZEA $(5$ e $10 \mu \mathrm{M}), 2 \mathrm{iP}(5$ e $10 \mu \mathrm{M}), \mathrm{BAP}$ $(5 \mu \mathrm{M})$ e testemunha. Essas diferenças constatadas em relação à altura das plantas e ao número de folhas por planta entre os tratamentos se explicam porque as microestacas vieram com diferentes tamanhos do experimento anterior. Pode-se observar, no entanto, que numa segunda avaliação após o transplante (Tabela 2), todos os tratamentos foram homogêneos e que as diferenças observadas nesta primeira avaliação foram dissipadas na continuação do crescimento das mudas.

Assim, observa-se que o tipo de citocinina utilizada no meio de cultura na fase de multiplicação não afetou o enraizamento e a sobrevivência das mudas nem o posterior desenvolvimento delas. Também, pode-se observar que o enraizamento ex vitro pode ser realizado com sucesso para amoreira-preta, eliminando uma etapa do processo de micropropagação, ao combinar numa só fase o enraizamento e a aclimatização, reduzindo o tempo e os custos de todo o processo. Além da redução dos custos, segundo Grattapaglia \& Machado (1998), há outra grande vantagem do enraizamento ex vitro, com a melhoria na qualidade do sistema radicular formado na planta, que se forma mais completo e funcional, com maior número de raízes secundárias, sem a formação intermediária de calo, que dificulta a conexão do sistema vascular entre caule e raiz.

No experimento de aclimatização após enraizamento in vitro, não foi encontrada interação entre os dois fatores testados (meio de cultura de enraizamento e método de aclimatização). Analisaram-se, portanto, as médias de cada fator, isoladamente.

Comparando-se a presença ou ausência de sacarose, podese observar que não houve diferença com relação à sobrevivência, enraizamento e número de folhas por planta (Tabela 3). Esses resultados diferem dos encontrados por Deng \& Donnelly (1993a) com framboesa, que observaram que a ausência de sacarose no meio de cultura de enraizamento levou a um aumento na fotossíntese e ao "endurecimento" das plantas in vitro.

No entanto, com relação à altura das plantas, o meio de cultura de enraizamento com sacarose foi superior ao meio de cultura sem sacarose (2,91 cm contra 2,28 cm). Esse resultado é similar ao encontrado por Deng \& Donnelly (1993a) e pode ser explicado pela baixa capacidade de fotossíntese das plantas in vitro. Por essa deficiência, haveria menor produção de carboidratos, que seriam insuficientes para os processos de formação de novas paredes celulares e de respiração.

No entanto, a ausência de sacarose somente levou a uma menor altura das plantas, não influenciando o número de folhas nem levando ao aumento a taxa de sobrevivência dos explantes. Pode-se supor que a cultivar de amoreira pesquisada in vitro não apresenta características totalmente heterotróficas, mesmo com meio de cultura com sacarose, diferente do citado por Donnelly \& Vidaver (1984), que constataram que a framboeseira in vitro tem uma mínima capacidade de metabolismo autotrófico. Outra hipótese, para o bom desempenho no meio de cultura sem sacarose, pode ser a utilização das reservas presentes na própria microestaca, que foram suficientes para o enraizamento e o crescimento das plantas, já que a avaliação foi realizada em curto espaço de tempo. Pode-se deduzir, ainda, para a cultivar testada, que não é necessário modificar as condições de cultivo in vitro sugeridas por Deng \& Donnelly (1993b), nem realizar um período de pré-aclimatização sugerido por Karakullukçu et al. (1993) e Silva et al. (1995).

Com relação ao método de aclimatização, o tratamento no túnel plástico levou a um maior crescimento das plantas $(3,04 \mathrm{~cm}$, contra $2,15 \mathrm{~cm}$ da câmara de nebulização), enquanto a câmara de nebulização levou a um maior número de folhas ( 9,7 contra 8,7 folhas por plantas no tratamento com túnel plástico) (Tabela 3). Apesar dessas diferenças encontradas, a porcentagem de sobrevivência, que é a variável mais importante analisada, foi idêntica entre os métodos testados, alcançando-se $100 \%$ de sobrevivência. Villa et al. (2006) também obtiveram alta taxa de sobrevivência (92\%) na aclimatização de amoreira-preta cv. Cherokee. Isso é bastante importante, pois de acordo com Donnelly \& Vidaver (1984), um dos maiores limites à produção comercial de plantas propagadas assepticamente é a baixa sobrevivência de plantas quando transferidas do meio de cultura ao solo.

Observou-se que foi possível aclimatizar a amoreira-preta cv. Brazos enraizada sem necessidade de nebulização intermitente. Essa condição de aclimatização das mudas pode reduzir os custos do processo de micropropagação, por não haver a necessidade de instalação de equipamentos de nebulização.

\section{CONCLUSÕES}

1) O enraizamento in vitro das microestacas da amoreirapreta cv. Brazos pode ser realizado sem a necessidade de imersão 
em solução de AIB e sem a adição de sacarose ao meio de cultura de enraizamento.

2) As citocininas utilizadas na fase de multiplicação não interferem significativamente no enraizamento e sobrevivência das plantas aclimatizadas.

3) A aclimatização das plantas enraizadas pode ser realizada em túnel plástico, sem a necessidade de nebulização, ou pode-se optar pelo enraizamento ex vitro e aclimatização em casa de vegetação com nebulização intermitente.

\section{REFERÊNCIAS}

ASSIS, T.F.; TEIXEIRA, S. L. Enraizamento de plantas lenhosas. In: TORRES, A.; CALDAS, L.S.; BUSO, J.A. Cultura de tecidos e transformação genética de plantas. Brasília: Embrapa-SPI/ Embrapa CNPH, 1998. v.1, p. 261-296.

AVITIA GARCÍA, E.; CASTILLO GONZÁLEZ,A. M. Enraizamento ex vitro de cuatro cultivares de zarzamora (Rubus spp.). Revista Chapingo, Chapingo, v.16, n.78, p.107-109, 1992.

BORGMAN, C. A.; MUDGE, K. W. Factors affecting the establishment and maintenance of 'Titan' red raspberry root organ cultures. Plant Cell, Tissue and Organ Culture, Dordrecht, v.6, p.127-137, 1986.

DANTAS, A.C. de M.; CERETTA, M.; FORTES, G.R. de L.; COUTINHO, E.F. Enraizamento in vitro da amoreira-preta (Rubus sp.), cultivar Caingangue. Agropecuária de Clima Temperado, Pelotas, v.3, n.2, p.123-130, 2000.

DENG, R.; DONNELLY, D. J. In vitro hardening of red raspberry by $\mathrm{CO}_{2}$ enrichment and reduced medium sucrose concentration. Hortscience, Alexandria, v.28, n.10, p.1.048-1.051, 1993a.

DENG, R.; DONNELLY, D. J. In vitro hardening of red raspberry through $\mathrm{CO}_{2}$ enrichment and relative humidity reduction on sugar-free medium. Canadian Journal of Plant Science, Ottawa, v.73, n.4, p. 1105-1113, 1993 b.

DONNELLY, D.J.; VIDAVER, W.E. Pigment content and gas exchange of red raspberry in vitro and ex vitro. Journal of the American Society of Horticultural Science, Alexandria, v.109, n.2, p.177181, 1984.

GRATTAPAGLIA, D.; MACHADO, M. A. Micropropagação. In: TORRES, A.; CALDAS, L. S.; BUSO, J. A. Cultura de tecidos e transformação genética de plantas. Brasília: Embrapa-SPI/ Embrapa CNPH, 1998. v.1, p. 183-260.
HOEPFNER, A.S.; NESTBY, R. Micropropagation of two red raspberry clones: effect of medium composition on multiplication, microshot size and rooting. Acta Agriculturae Scandinavica, Stockholm, v.41, n.3, p.285-293, 1991.

HOEPFNER, A. S.; NESTBY, R.; NYBOM, H. Genetic deviation initiated by adventitious shoot regeneration from tissue cultured red raspberry. Journal of Horticultural Science, Ashford, v.71, n.1, p.71-79, 1996.

JIN, W.; GU, Y.; ZHEN, S.-Z. In vitro propagation of Rubus species. Scientia Horticulturae, Amsterdam, v. 49, n. 3-4, p. 335-340, 1992.

KARAKULLUKÇU, S; AGAOGLU, Y. S.; ABAK, K. Effect of different auxin-cytokinin combinations on the in vitro propagation of raspberry cv. Schonemann. Acta Horticulturae, Wageningen, n.352, p.127-132, 1993.

MURASHIGE, T.; SKOOG, F. A revised medium for rapid growth and bio assays with tobacco tissue cultures. Physiologia Plantarum, Copenhagen, v.15, p.473-497, 1962.

RADMANN, E.B.; GONÇALVES, E.D.; FORTES, G.R. de L. Concentrações de ácido indolbutírico e períodos de escuro no enraizamento in vitro de amoreira-preta (Rubus spp.), cv. Ébano. Revista Brasileira de Fruticultura, Jaboticaval, v.25, n.1, p.124126, 2003.

RAMIREZ DEL CASTILLO, A.; ANGARITAZERDA, A. Estudios preliminares para la propagacion clonal in vitro de mora (Rubus glaucus L.). Agronomía Colombiana, Bogotá, v.7, n.1-2, p.1725, 1990.

SILVA, A.T.; PASQUAL, M.; ISHIDA, J.S.; ANTUNES, L.E.C. Aclimatação de plantas provenientes da cultura in vitro. Pesquisa Agropecuária Brasileira, Brasília, v.30, n.1, p.43-48, jan. 1995.

SOBCZYKIEWICZ, D. Micropropagation of raspberry (Rubus idaeus L.). In: BAJAJ, Y. P. S. High-tech and micropropagation II. Berlin Heidelberg: Springer-Verlag, 1992. p.339-353. (Biotechnology in agriculture and forestry, 19).

VILLA, F.; PASQUAL, M. ARAÚJO, A.G. de; PIO, L.A.S. Micropropagação da amoreira-preta (Rubus spp.) e efeito de substratos na aclimatização de plântulas. Acta Scientiarum, Maringá, v. 28, n. 1, p. 47-52, 2006. 